\title{
Impact of sea breeze on wind-seas off Goa, west coast of India
}

\author{
S Neetu ${ }^{1, *}$, Satish Shetye ${ }^{1}$ and P Chandramohan ${ }^{2}$ \\ ${ }^{1}$ Physical Oceanography Division, National Institute of Oceanography, Dona Paula, Goa 403 004, India. \\ ${ }^{2}$ Indomer Coastal Hydraulics (P) Ltd, Ragamalika, Kumran Colony Main Road, Vadapalani, \\ Chennai 600 026, India. \\ *e-mail: neetu@nio.org
}

\begin{abstract}
After withdrawal of the Indian Summer Monsoon and until onset of the next monsoon, i.e., roughly during November-May, winds in the coastal regions of India are dominated by sea breeze. It has an impact on the daily cycle of the sea state near the coast. The impact is quite significant when large scale winds are weak. During one such event, 1-15 April 1997, a Datawell directional waverider buoy was deployed in $23 \mathrm{~m}$ water depth off Goa, west coast of India. Twenty-minute averaged spectra, collected once every three hours, show that the spectrum of sea-breeze-related 'wind-seas' peaked at $0.23 \pm 0.05 \mathrm{~Hz}$. These wind-seas were well separated from swells of frequencies less than $0.15 \mathrm{~Hz}$. The TMA spectrum (Bouws et al 1985) matched the observed seas spectra very well when the sea-breeze was active and the fetch corresponding to equilibrium spectrum was found to be $77 \pm 43 \mathrm{~km}$ during such occasions. We emphasize on the diurnal cycle of sea-breeze-related sea off the coast of Goa and write an equation for the energy of the seas as a function of the local wind.
\end{abstract}

\section{Introduction}

While the importance of seasonally reversing monsoon winds to ocean processes in the Indian coastal region has been well appreciated, virtually no attention has been paid in the available literature to diurnal winds along the coast. After withdrawal of the Indian Summer Monsoon and until onset of the next monsoon, i.e., roughly during NovemberMay, winds in the coastal region of India are dominated by sea breeze. Studies carried out elsewhere have shown that sea breeze can have a significant impact on coastal processes. For example, it has been shown that sea breeze has important implications to alongshore sediment transport in the coastal areas off Perth, Australia (Masselink et al 1998a, b; Pattiaratchi et al 1997). Most often the impact of sea breeze is felt because of the wave field that is excited by the breeze in the shallow areas near the coast. This paper examines the impact of the breeze on near-shore waves off the west coast of India using wave data collected with a Datawell directional waverider buoy in $23 \mathrm{~m}$ of water, and winds from a location close to the coastline and nearer the buoy position. Simultaneous wind and wave measurements were made during June 1996 to May 1997 off Goa (Mormugao), central west coast of India (figure 1) to record the sea breeze effect as most of the Indian coast experience it. Here we focus on the first two weeks of April 1997, when the winds showed a distinct seabreeze cycle and its impact was seen on the prevailing waves. During April, the large-scale circulation over India and the north Indian Ocean is generally weak, this being the transition time between the northeast monsoon and the southwest monsoon (see Shetye and Gouveia 1998, for a description of the environment along the coast). It is therefore expected that the swells at the location of observation would be minimal at this time.

Keywords. Wind-wave; sea breeze; coastal processes; energy density spectra; Arabian Sea.

J. Earth Syst. Sci. 115, No. 2, April 2006, pp. 229-234

(C) Printed in India. 


\section{Depth (Km)}
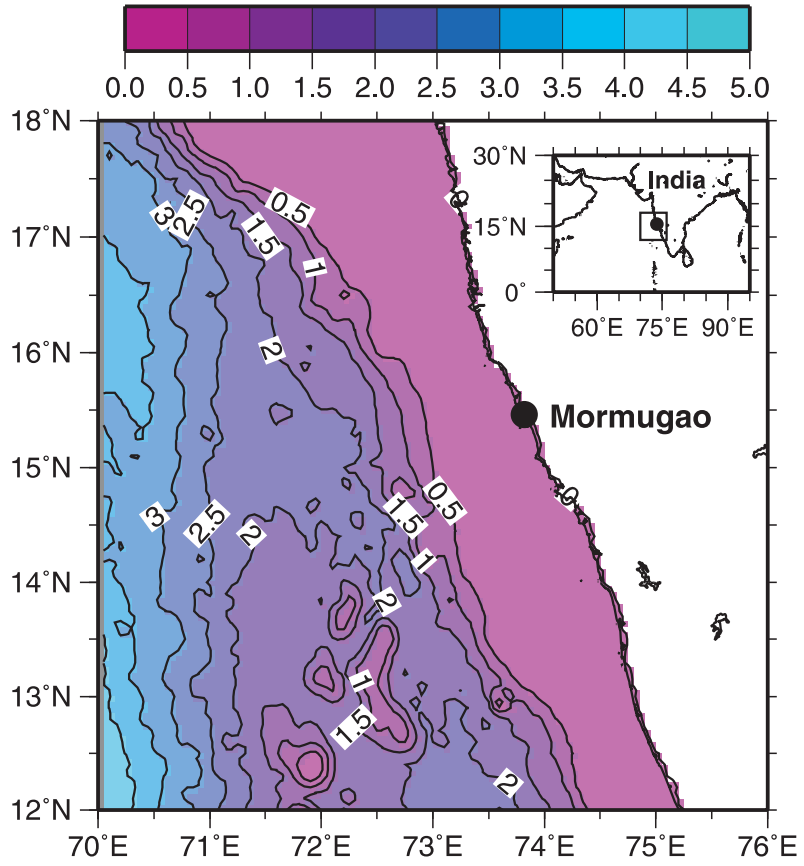

Figure 1. Location of the wind and wave observations reported in the paper (bottom topography contours are in $\mathrm{kms})$.

\section{Observations and analysis}

The wind observations were made using an anemometer located on the terrace of the main building of the National Institute of Oceanography, Goa. The building is on the coast and is approximately $28 \mathrm{~km}$ from the wave rider buoy location. The height of the anemometer was about $50 \mathrm{~m}$ above sea level. The recorded data were ten-minute vector averages of wind speed and direction. During the period of study the winds usually picked up at 1000 hours (IST) and peaked around 1500 hours and the peak wind speed remained around $5 \mathrm{~m} / \mathrm{s}$ (figure 2a upper panel). By 2000 hours the winds dropped below $3 \mathrm{~m} / \mathrm{s}$ and decreased slowly thereafter. The mean daily hodograph traced by the wind vector during the period of study is shown in figure 3 . The hodograph is elliptical with wind towards the land from about $1030 \mathrm{hrs}$. As the wind picked up, the wind vector turned towards the right. By $1800 \mathrm{hrs}$ the wind was approximately alongshore. The vector continued to turn towards its right. Subsequently wind magnitude decreased. During early morning hours the wind had a component oriented towards the sea: this is the land breeze. Its magnitude was much weaker than that of the sea breeze. In fact, minimal wind speed of about $1.5 \mathrm{~m} / \mathrm{s}$ was observed around 0600 hours. Before commencement of the sea breeze, the wind speed generally remained less than $2 \mathrm{~m} / \mathrm{s}$. The onset of sea breeze was marked by an abrupt change in wind direction. The wind was from about $90^{\circ}$ before $1000 \mathrm{hrs}$ and after onset of sea breeze the direction changed to about $300^{\circ}$ (figure 2a lower panel). During 1000-2000 hours the wind direction changed slowly from $300^{\circ}$ to about $360^{\circ}$. The coastline in the vicinity of Goa is oriented along approximately $340^{\circ}$ (figures 1 and 3). Hodographs similar to the one shown in figure 3 have been observed at Kinloss and Aberdeen, Scotland (Simpson 1994). Hence, the sea breeze at a height of about $50 \mathrm{~m}$ above sea level recorded by the anemometer is almost oriented along the coastline. At sea level, the breeze is expected to be at an angle somewhat lower than the angle at the height of the anemometer owing to veering from frictional effects in the atmospheric boundary layer.

The observed 20-minute averaged wave spectra during the first two weeks of April 1997, was computed once every three hours over the $0.03-0.6 \mathrm{~Hz}$ frequency band. Wind-wave spectrum $1-30 \mathrm{sec}$ could be separated invariably into two distinct parts (figure 4). The lower frequency part corresponds to swell waves of frequencies lesser than $0.15 \mathrm{~Hz}$. The higher frequency part which corresponds to the sea waves, reveals a distinct diurnal cycle. This part of the spectrum was isolated and analyzed in greater detail. The spectrum peaked at $0.23 \pm 0.05 \mathrm{~Hz}$. The mean direction during 1000 2000 hours was around $300^{\circ}$ when sea breeze was usually active (figure $2 \mathrm{~b}$ ). The mean wave direction deviates, by about $30^{\circ}$ than the average angle of sea breeze measured by the anemometer $\left(330^{\circ}\right)$. This difference may be attributed to the veering of wind angle in the boundary layer. However, these two directions were close enough to support the idea that the high frequency part of the spectrum was primarily due to the effect of local winds.

To investigate this possibility further, we identified the peak frequency of the wind-sea component of the observed spectrum, and fitted a theoretical equilibrium spectrum. The theoretical spectrum chosen was the TMA spectrum (Bouws et al 1985), formulated as an extension of the JONSWAP spectrum (Hasselmann et al 1973) for wind-generated seas in a finite water depth. The depth was taken to be $23 \mathrm{~m}$. The JONSWAP spectrum is:

$$
\begin{aligned}
S(f) & =\frac{\alpha g^{2}}{(2 \pi)^{4} f^{5}} \exp \left(-1.25\left(\frac{f_{m}}{f}\right)^{4}\right) \gamma^{\tau}, \\
\tau & =\exp \left(-\frac{\left(f-f_{m}\right)^{2}}{2 \sigma^{2} f_{m}^{2}}\right),
\end{aligned}
$$

where $\gamma=$ peak-shape parameter (average value 3.30), $\alpha=0.076 \bar{x}^{-0.22}, \sigma=0.07, f \leq f_{m}$ and 0.09 , $f>f_{m}, f_{m}=3.5(g / \bar{U}) \bar{x}^{-0.33}, x$ is the fetch length, $\bar{x}=g x / \bar{U}^{2}$ is the dimensionless fetch, $\bar{U}$ is the 
(a)
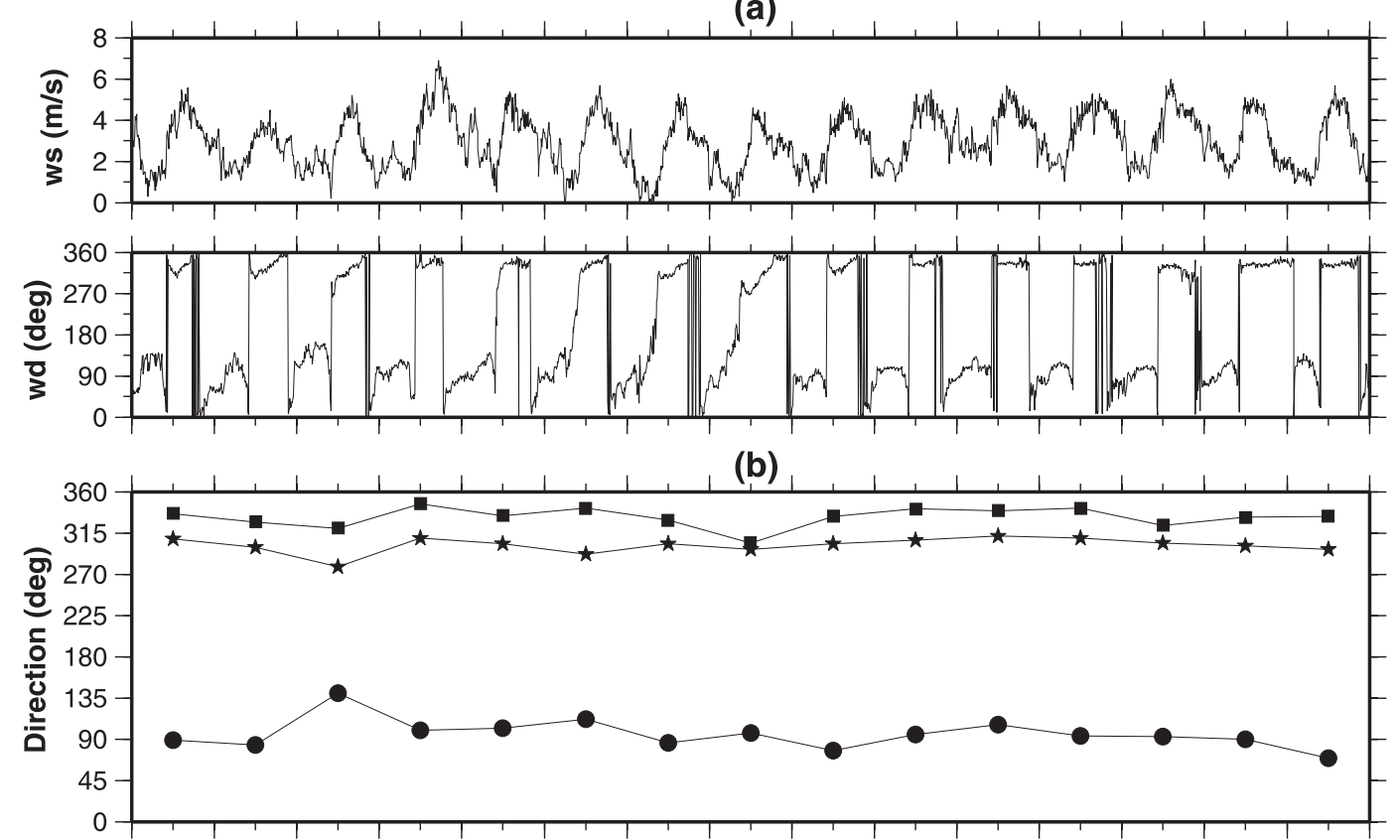

(c)

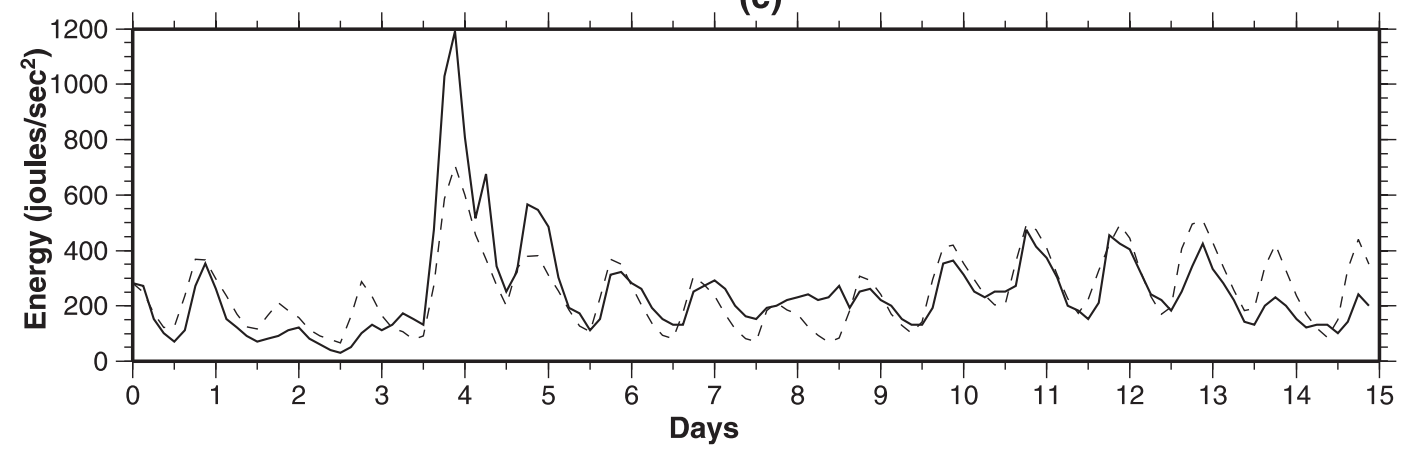

Figure 2. (a) Upper panel: wind speed (m/s) during 1-15 April 1997. Lower panel: same as upper panel except wind direction (degree). The horizontal axis covers the time span from 0000 hrs on 1 April 1997 to 0000 hrs on 16 April 1997 . ws: wind speed; wd: wind-direction. (b) Daily variation of wind and wave direction. Solid circles indicate average wind direction during 0000-1000 hrs; wind direction during 1000-2000 hrs is shown by solid squares; stars give average wave direction. (c) Comparison of total wave energy calculated from wave-rider buoy data (solid line) and calculated by equation (dashed line).

mean wind speed and $g$ is the acceleration due to gravity.

The spectrum represents wind-generated seas with fetch limitation. Wind speed and fetch length are inputs for the above spectrum while the peak frequency was identified from the observed spectrum. Bouws et al (1985) applied a transformation factor to the JONSWAP spectrum and defined the TMA spectrum as follows:

$$
S(f)=S(f) \cdot \phi\left(\omega_{h}\right)
$$

where

$$
\phi\left(w_{h}\right)=\frac{(k(w, h))^{-3} \frac{\partial}{\partial w} k(w, h)}{(k(w, \infty))^{-3} \frac{\partial}{\partial w} k(w, \infty)} .
$$

In the above transformed formulation $w_{h}$ is a dimensionless frequency defined by $2 \pi f \sqrt{(h / g)}$ where $h$ is the water depth and $k(w, h)$ is the wave number associated with the dispersion relationship for waves in finite water depth.

The TMA spectrum that could provide the best fit for the sea-related observed spectrum off Goa, was determined by choosing the equivalent fetch and wind speed that minimized the sum of squares of departure between the observed and the theoretical spectra. The results of this exercise on a typical day is summarized in figure 5. The spectrum showed distinct diurnal variability. The energy due to the spectrum peaked around 1800-2000 hours.

The wind speed determined from the bestfit theoretical spectrum and that measured by the anemometer for the corresponding 20-minute period were well correlated when the computed wind speed was in excess of $2 \mathrm{~m} / \mathrm{s}$ (figure 6 ). The correlation between the observed and estimated 


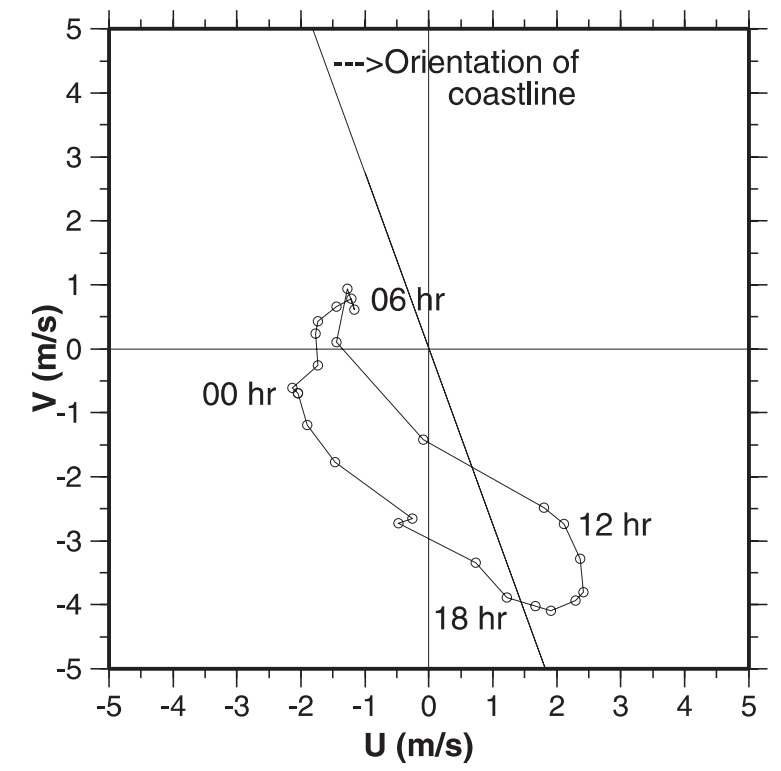

Figure 3. Sea breeze hodograph for the average of 1-15 April 1997. The wind vectors at 0600, 1200, 1800 and 0000 hours are identified. Though there is day-to-day variation in the sea breeze as seen in figure 2(a), on an average the sea breeze at about 1200 hours is approximately from the northwest. At this time the wind has a component perpendicular to the coastline and oriented towards the coast (see orientation of the coastline marked). By 1800 hours the wind vector turns towards the right to a direction that is along the coast, and continues to turn further while the magnitude decreases. wind speeds was 0.64 (for 39 points), which is well above the $99 \%$ significance level $(\sim 0.4)$ and supports the argument that the observed spectrum was mostly in equilibrium with the local wind when the sea breeze was active with speed in excess of $2 \mathrm{~m} / \mathrm{s}$. The fetch corresponding to the equilibrium spectrum was found to be $77 \pm 43 \mathrm{~km}$ during such occasions. The least-square fit through the points marked in figure 6 was $y=0.5426 x+1.2264$, where $y$ is the observed wind and $x$ is the wind equivalent of the wave spectrum. The wave spectral energy peaked around 1800-2000 hours though the onset of the sea breeze was around 1000 hours; maximum wind speed was observed at 1500 hours.

It is known from empirical data that there is always a lag between onset of wind and the time at which maximum wave energy is attained. Empirical formulae for wave growth, which have been derived from large data sets (WMO-No. 702, 1988), state that for the wind speed of $\sim 5 \mathrm{~m} / \mathrm{s}$ and fetch $\sim 77 \mathrm{~km}$, the time at which the maximum wave growth takes place is approximately 9 hours. After this period, wave growth becomes saturated. This is the reason for the time lag between the maximum wind speed and the resultant wave spectra having maximum energy.

Our analysis of the wind and wave data indicates that, the higher frequency peak of the wave

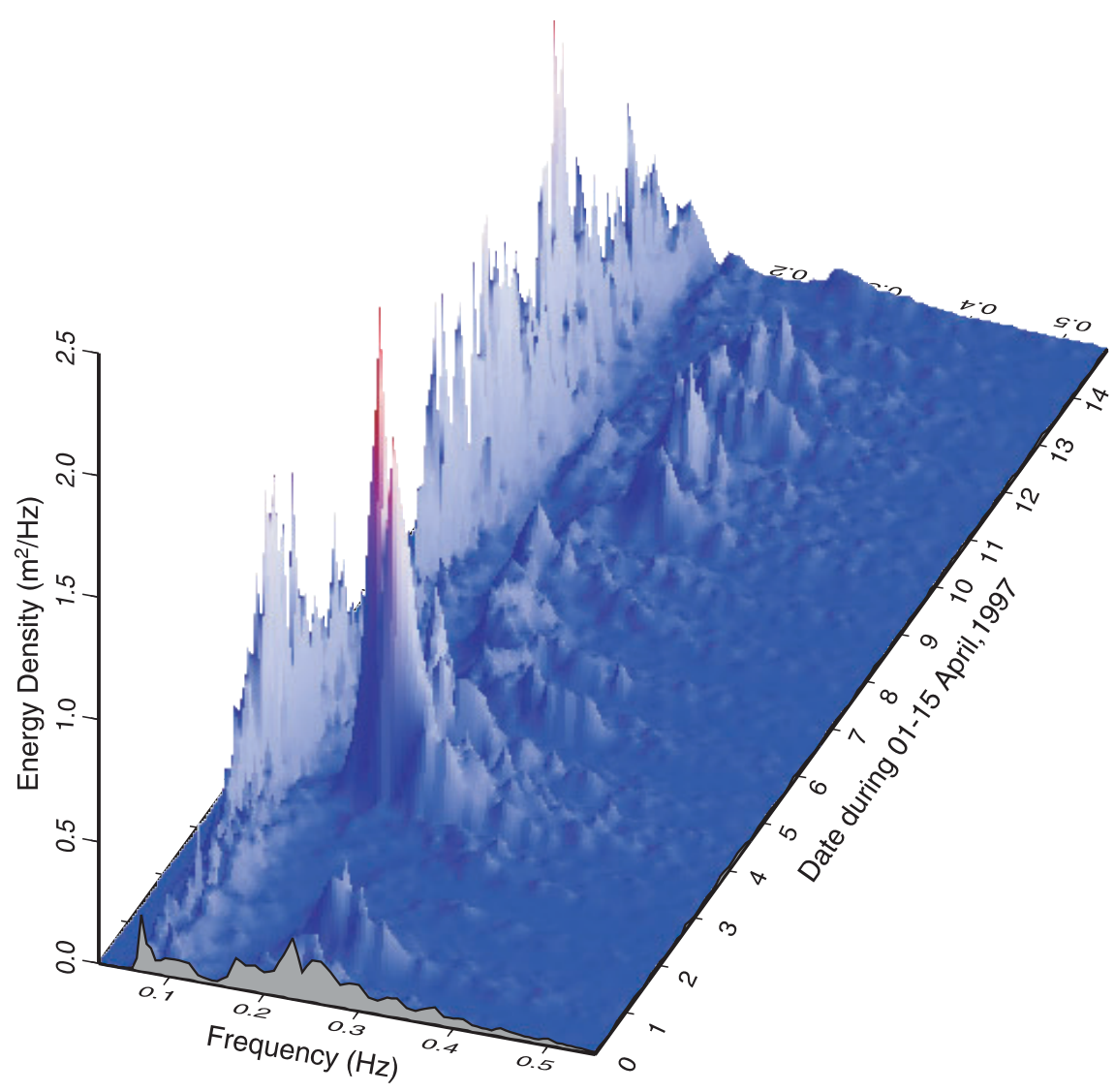

Figure 4. Spectral density $\left(\mathrm{m}^{2} / \mathrm{Hz}\right)$ as a function of frequency $(\mathrm{Hz})$ and time (3 hourly interval) during 1-15 April 1997. Along the time axis, 0000 hours on 1 April 1997 is given by zero. 


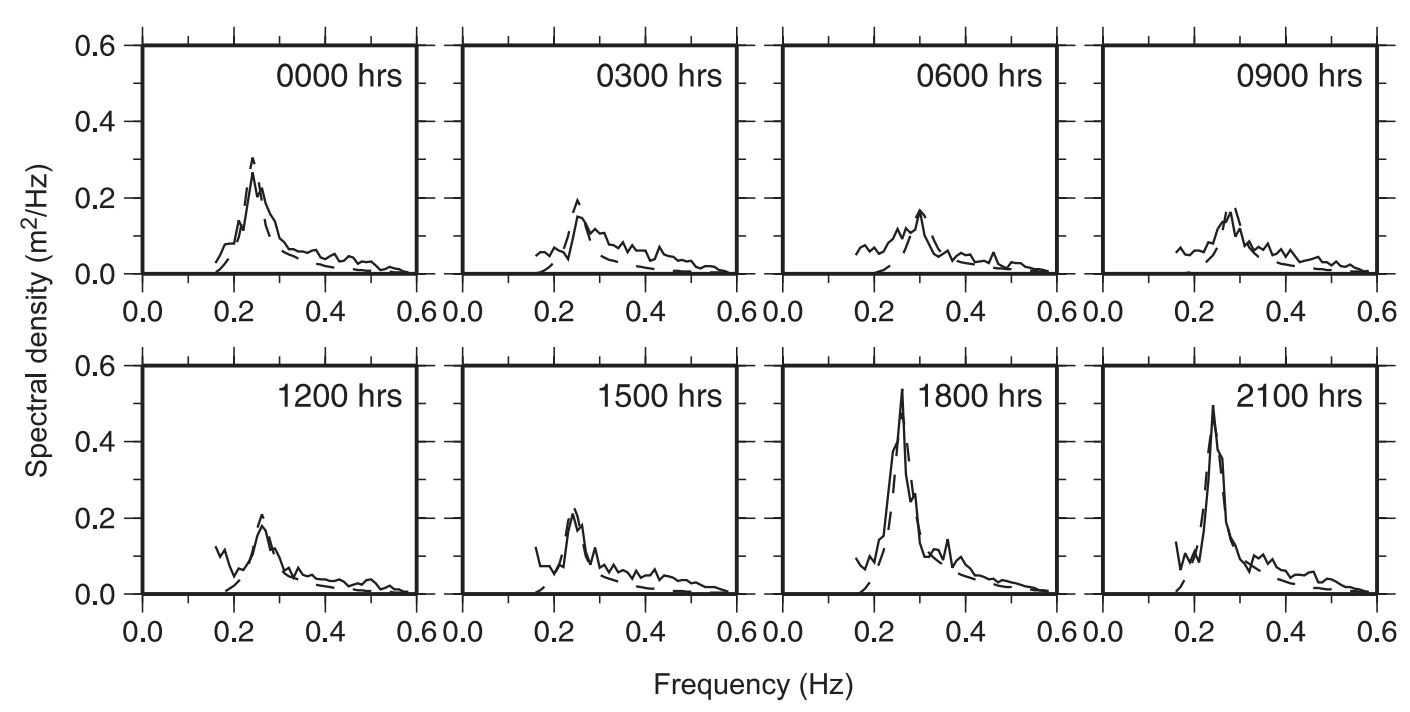

Figure 5. Computed best-fit theoretical spectrum (dashed line) and the observed spectrum (solid line) on 11 April 1997.

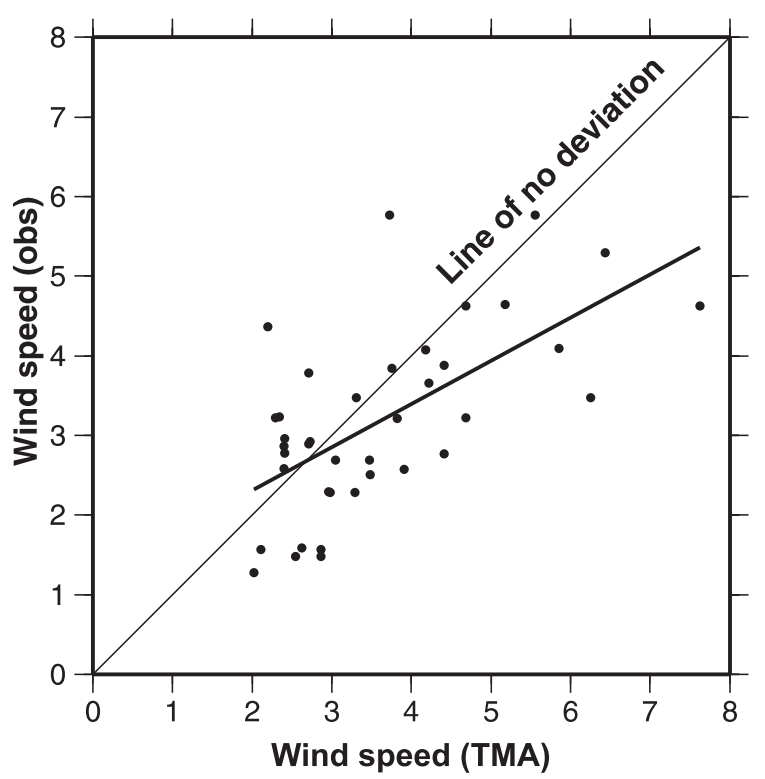

Figure 6. Each point gives wind speed $(\mathrm{m} / \mathrm{s})$ calculated from TMA spectra versus observed wind speed $(\mathrm{m} / \mathrm{s})$. The line is the least-squares fit to all the points.

spectrum (figure 4) was forced by local winds alone. This implies that the energy associated with this wind-sea spectrum should be a function of the local wind speed. More specifically, the diurnal variability of the energy under the spectrum should be associated with diurnal variability of the winds. This may be expressed as,

$$
\frac{d E}{d t}=\alpha_{1} \bar{U}^{3}-\alpha_{2} E
$$

where $E$ is the wave energy, $\bar{U}$ is the mean wind speed, and $\alpha_{1}$ and $\alpha_{2}$ are constants. The first term on the right hand side represents the generation term. The energy transmitted to the water column by wind has been taken to be proportional to $\bar{U}^{3}$ following Denman (1973) who used a similar parameterization in connection with energy entering the ocean surface mixed-layer. The second term on the right hand side is the dissipation term. The values of $\alpha_{1}$ and $\alpha_{2}$ were chosen so as to get the best fit to the observed variation. The observed energy and the one computed from the above equation is given in figure 2(c). Values of the constants used in the computed spectrum were $\alpha_{1}=1.93 \times 10^{-4}$, and $\alpha_{2}=3.0 \times 10^{-5}$. Comparison of the observed and computed energy shown in figure 2(c) encourages us to conclude that the high-frequency peak of the spectrum represents the wind-seas forced by local wind activity or sea breeze.

\section{Summary and conclusions}

The analysis in the present study was restricted to the period 1-15 April 1997; the correlation between wind speed inferred from the TMA spectrum and the observed wind speed (figure 6) was quite significant for this period. This appears to be due to the contribution to the high frequency peaks arising from the wind-seas. Contribution of the swell waves was insignificant for the period studied here. March-April are the months during which transition from northeast monsoon (NovemberFebruary) to the much stronger winds of the southwest monsoon occurs. Along the west coast of India the winds due to the latter generally start blowing from the west in May. They strengthen once the monsoon sets in. The period we have analyzed is therefore rather special: the large-scale winds were particularly weak and hence the diurnal cycle due to sea breeze could be identified. 


\section{Acknowledgement}

The authors from NIO wish to thank the Department of Ocean Development, New Delhi for financial support. This is NIO contribution 4054 .

\section{References}

Bouws E, Gunter H, Rosenthal W and Vincent C L 1985 Similarity of the wind wave spectrum in finite water depth: 1. Spectral form; J. Geophys. Res. 90 C1 975-986.

Denman 1973 A time-dependent model of the upper ocean; J. Phys. Oceanogr. 3 173-184.

Guide to wave analysis and forecasting 1988 WMONo. 702 .
Hasselmann K et al 1973 Measurement of wind-wave growth and swell decay during the Joint North Sea Wave Project (JONSWAP); Dtsch. Hydrogr. Inst., Hamburg.

Masselink G and Pattiaratchi C B 1998a The effects of sea breeze on beach morphology, surf zone hydrodynamics and sediment resuspension; Marine Geology 146 115-135.

Masselink G and Pattiaratchi C B 1998b Morphodynamic impact of sea breeze activity on a beach with beach cusp morphology; J. Coast. Res. 14/2 393-406.

Pattiaratchi C B, Hegge B, Gould J and Eliot I 1997 Impact of sea-breeze activity on nearshore and foreshore processes in southwestern Australia; Cont. Shelf Res. 17/13 1539-1560.

Shetye S R and Gouveia A D 1998 Coastal circulation in the North Indian Ocean - Coastal Segment (14, S-W). In: The Global Coastal Ocean: Regional Studies and Syntheses (eds) Robinson A R and Brink K H, The Sea 11 523-556.

Simpson J E 1994 Sea Breeze and local wind (Cambridge University Press). 